\title{
Investigation of the Structure and Properties of Deformed Semi- Finished Products from Alloys of the Al-REM System Made by the Method of Ingotless Rolling-Extruding
}

\author{
Vadim BESPALOV $^{1}$, Sergey SIDELNIKOV ${ }^{1}$, Viktor BERNGARDT ${ }^{1}$, \\ Denis VOROSHILOV ${ }^{1, a^{*}}$, Olga YAKIVYUK ${ }^{1}$, Timofey BERMESHEV ${ }^{1}$, \\ Alexander DURNOPYANOV ${ }^{1}$, Elena KULISHOVA ${ }^{1}$, \\ Marina VOROSHILOVA ${ }^{1}$ \\ ${ }^{1}$ Siberian Federal University, Russia, 660025, Krasnoyarsk, Krasnoyarskiy Rabochiy ave., 95 \\ ae-mail: sibdrug@mail.ru
}

Keywords: aluminum alloys, rare-earth metals, ingotless rolling-extruding, zirconium, cerium, lanthanum, annealing, microstructure, mechanical properties, heat resistance, electrical conductivity.

\begin{abstract}
The article presents the investigation results of the structure and properties of rods of aluminum alloys containing zirconium, cerium and lanthanum after ingotless rolling-extruding (IRE) and heat treatment. The patterns of changes in the microstructure, mechanical properties, electrical resistivity depending on the chemical composition of the alloys, processed by the IRE method and various modes of rods annealing are shown. A metallographic analysis of the grain structure of the samples in a deformed state and after annealing performed. The temperatures at which the alloy structure remains stable and maintains the level of operational properties revealed. The effect of chemical composition on the heat resistance of deformed semi-finished products represented. The study made it possible to evaluate the level of properties of experimental alloys after processing by the method of ingotless rolling-extruding and various modes of rods annealing.
\end{abstract}

\section{Introduction}

The development of the automotive industry, modern transport systems and small aircraft determines the demand of enterprises for conductive products with the lowest possible weight, high level of strength and heat resistance. Therefore, an urgent task for production is the introduction of new methods for the manufacture of longish rods from aluminum alloys with an improved set of mechanical and electrical properties [1-4].

One of the ways to improve the quality of deformed semi-finished products is the introduction into production method of ingotless rolling-extruding (IRE) of rods with circular cross-section from aluminum alloys alloyed with rare-earth metals such as zirconium, cerium and lanthanum. The IRE method, due to the peculiarities of the stress-strain state scheme consisting in comprehensive non-uniform extrusion and shear deformation, will significantly increase the strength and ductility of extruded products, and alloying with rare-earth metals ensures the stability of their properties with increasing operating temperature [1-14].

The aim of the work is to investigate the structure and properties of rods from aluminum alloys containing zirconium, cerium and lanthanum, made by the method of ingotless rollingextruding and assess the effect of annealing on their change.

\section{Methods of carrying out researches}

Ingotless rolling-extruding performed at the CRE-200 laboratory processing unit [1], the scheme of which is shown in Figure 1. The melt from the furnace-mixer 1 through the receiving device 2 , which regulates the metal supply, was poured into a closed section gauge formed by a roll with a protrusion 3 and a roll with a groove 4 , in which the metal crystallized, rolled, extruded through a gauge hole of the extruding die 5, pressed against the rolls by a annular hydraulic 
cylinder 6 , in the form of a rod of circular cross section and fed by a guiding device 7 into the coiler 8 .

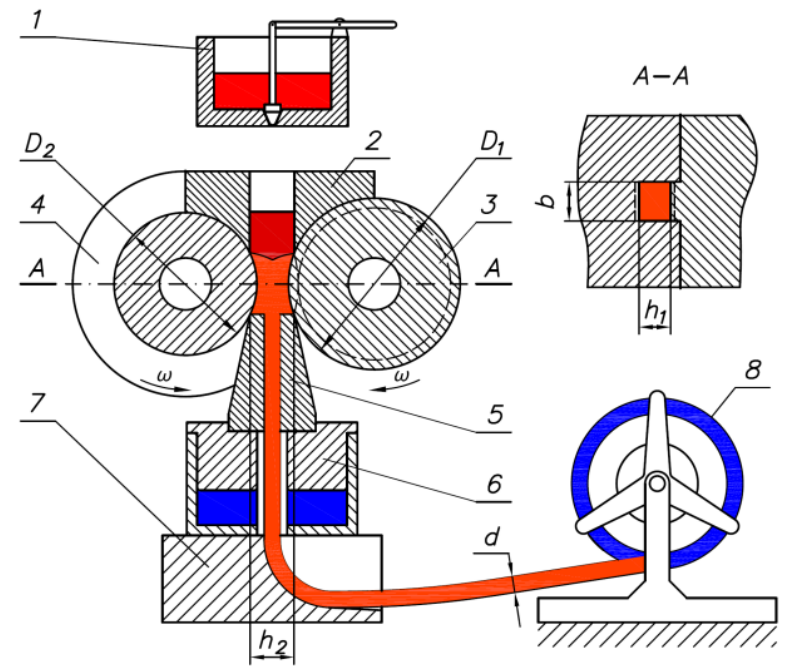

Fig. 1 laboratory processing unit CRE-200 [1]: 1 - furnace-mixer;

2 - receiving device; 3 - roll with a protrusion; 4 - roll with a groove; 5 - extruding die, 6 - annular hydraulic cylinder; 7 - guiding device; 8 - coiler

The diameter of the rolls along the protrusion $D_{1}=214 \mathrm{~mm}$; along the bottom of a stream of caliber $D_{2}=167 \mathrm{~mm}$; caliber width $b=15 \mathrm{~mm}$; minimum caliber height on the common axis of the rolls $h_{1}=7 \mathrm{~mm}$; extruding die mirror height $h_{2}=20 \mathrm{~mm}$; diameter of extruded rods $d=9$ $\mathrm{mm}$. The technological parameters of the process were as follows: the temperature of pouring the melt into the caliber of the rolls was $800{ }^{\circ} \mathrm{C}$; roll temperature $100{ }^{\circ} \mathrm{C}$; the frequency of rotation of the rolls $\omega=4 \mathrm{rpm}$. The degree of deformation during rolling was $50 \%$, the drawing ratio in the extruding zone was 4.4 , and the strain rate was $0.74 \mathrm{~s}^{-1}$. The chemical composition of the alloys is given in table 1 .

Table 1 The chemical composition of the alloys, mass \%

\begin{tabular}{|c|c|c|c|c|c|c|}
\hline Alloy number & $\mathrm{Al}$ & $\mathrm{Ce}$ & $\mathrm{La}$ & $\mathrm{Zr}$ & $\mathrm{Fe}$ & $\mathrm{Si}$ \\
\hline 1 & 99.4 & - & - & 0.30 & 0.20 & 0.10 \\
\hline 2 & Basis & 0.5 & - & - & - & - \\
\hline 3 & Basis & 4.58 & 2.48 & - & 0.22 & 0.10 \\
\hline
\end{tabular}

To assess the change in the properties of the rods after heating, annealing was performed at temperatures of $230-450{ }^{\circ} \mathrm{C}$. The yield strength $R_{p}$, the ultimate tensile strength $R_{m}$, and the elongation to failure $A$ determined by the tensile method on a Walter Bai AG LFM 20 machine, the lectrical resistivity $\rho$ of the rods measured with a "Vitok" ohmmeter on samples 1 meter long. The microstructure of the rods was studied using a Carl Zeiss Observer 7 Mat optical microscope and a FEI Quanta FEG 650 scanning electron microscope with an Oxford X-MaxN energy dispersive spectrometer. The nature of the grain distribution after deformation and annealing was revealed by oxidizing the surface of the sections in the Barker reagent at the Struers LectroPol-5 electrolytic polishing and etching unit.

\section{Results and its discussion}

The study results of the properties of rods after ingotless rolling-extruding and annealing are shown in Table 2 and Fig. 2. Increasing the annealing temperature from 230 to $450{ }^{\circ} \mathrm{C}$ leads to a decrease in the ultimate tensile strength $R_{m}$ and an increase in the elongation to failure $A$ (Fig. 2).

Table 2 Properties of rods after IRE

\begin{tabular}{|l|l|l|l|l|l|l|}
\hline Alloy & Condition & $T,{ }^{\circ} \mathrm{C}$ and & $R_{p}, \mathrm{MPa}$ & $R_{m}, \mathrm{MPa}$ & $A, \%$ & $\rho$, \\
\hline
\end{tabular}




\begin{tabular}{|c|c|c|c|c|c|c|}
\hline & & holding time, $\mathrm{h}$ & & & & Ohm·mm ${ }^{2} / \mathrm{m}$ \\
\hline \multirow{4}{*}{1} & IRE & - & 125 & 140 & 25 & 0.0330 \\
\cline { 2 - 7 } & Annealed & $230,1 \mathrm{~h}$ & 112 & 125 & 30 & - \\
\cline { 2 - 7 } & Annealed & $300,1 \mathrm{~h}$ & 108 & 120 & 35 & - \\
\cline { 2 - 7 } & Annealed & $400,1 \mathrm{~h}$ & 76 & 85 & 40 & - \\
\cline { 2 - 7 } & Annealed & $450,10 \mathrm{~h}$ & 70 & 80 & 45 & 0.0319 \\
\hline \multirow{4}{*}{2} & IRE & - & 104 & 115 & 25 & 0.0290 \\
\cline { 2 - 7 } & Annealed & $230,1 \mathrm{~h}$ & 100 & 110 & 35 & - \\
\cline { 2 - 7 } & Annealed & $300,1 \mathrm{~h}$ & 95 & 105 & 40 & - \\
\cline { 2 - 7 } & Annealed & $400,1 \mathrm{~h}$ & 70 & 80 & 45 & - \\
\cline { 2 - 7 } & Annealed & $450,10 \mathrm{~h}$ & 65 & 80 & 60 & 0.0287 \\
\hline \multirow{6}{*}{3} & IRE & - & 170 & 190 & 20 & 0.0310 \\
\cline { 2 - 7 } & Annealed & $230,1 \mathrm{~h}$ & 155 & 175 & 25 & - \\
\cline { 2 - 7 } & Annealed & $300,1 \mathrm{~h}$ & 150 & 170 & 30 & - \\
\cline { 2 - 7 } & Annealed & $400,1 \mathrm{~h}$ & 135 & 150 & 35 & - \\
\cline { 2 - 7 } & Annealed & $450,10 \mathrm{~h}$ & 125 & 140 & 40 & 0.0310 \\
\hline
\end{tabular}
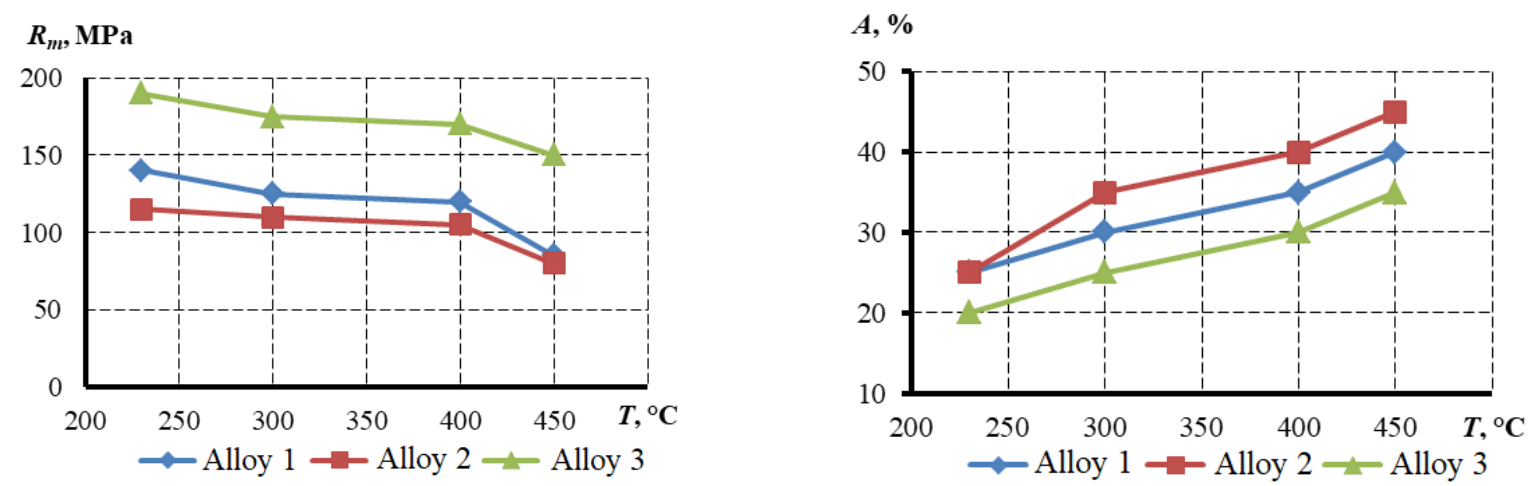

Fig. 2 Mechanical properties of the rods: $R_{m}$ - ultimate tensile strength, MPa; $A$ - elongation to failure, $\% ; T$ - temperature of annealing, ${ }^{\circ} \mathrm{C}$

The ultimate tensile strength of the rods $R_{m}$ after the IRE of alloy 1 is $140 \mathrm{MPa}$, alloy 2 has $115 \mathrm{MPa}$ and alloy 3 has $190 \mathrm{MPa}$. The minimum value of the electrical resistivity $\rho=0.0290$ $\mathrm{Ohm} \cdot \mathrm{mm}^{2} / \mathrm{m}$ in the deformed state has rods from alloy 2 at a value of ultimate tensile strength $R_{m}$ $=115 \mathrm{MPa}$. The elongation to failure $A$ of samples after IRE is in the range of 20-25\%, which indicates a high level of plasticity of the rods in the deformed state.

Annealing of rods from alloys 1,2 , and 3 at a temperature of $230{ }^{\circ} \mathrm{C}$ for 1 hour reduces $R_{m}$ to values of 125,110 , and $175 \mathrm{MPa}$, respectively. A further increase of annealing temperature leads to even more softening, thus, rods from the 1st alloy doped with zirconium in an amount of $0.3 \%$ retain a strength level sufficient for subsequent processing after heating at $300{ }^{\circ} \mathrm{C}$, rods from alloy 2 with a content of $0.5 \%$ cerium lose strength when heated above $230{ }^{\circ} \mathrm{C}$. A higher strength level of $140 \mathrm{MPa}$ after annealing at $450{ }^{\circ} \mathrm{C}$ for 10 hours provides alloy composition 3 with cerium content of $4.58 \%$.

The results of the study of the structure are presented in Figures 3-5.

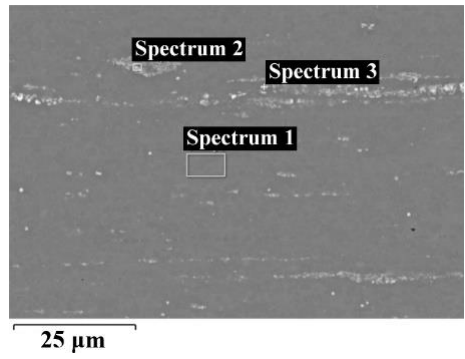

$a$

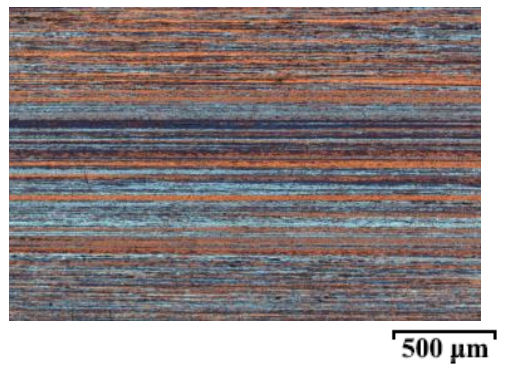

$b$

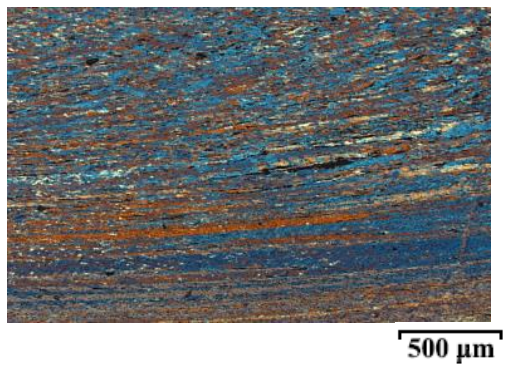

$c$ 


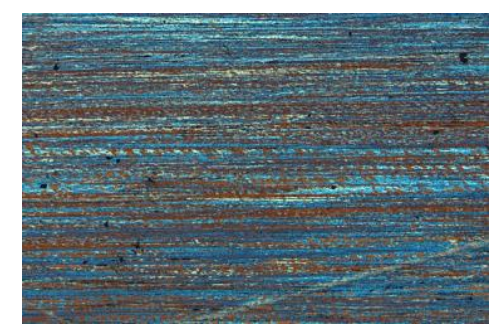

$\mathbf{5 0 0 \mu m}$

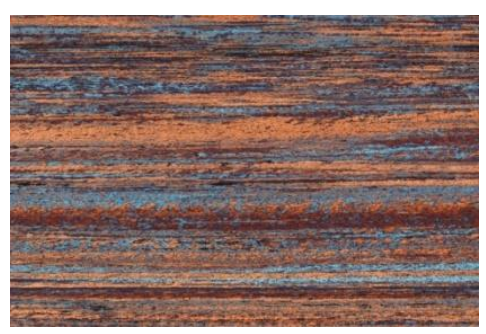

$\overline{500 \mu \mathrm{m}}$

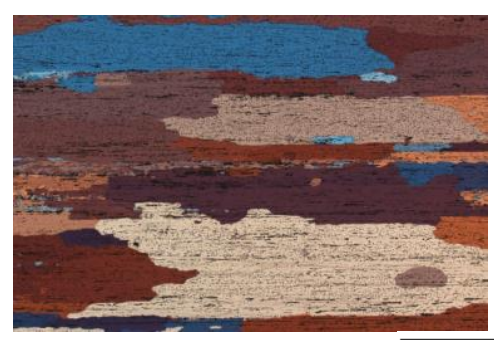

$\overline{500 \mu \mathrm{m}}$

\begin{tabular}{|c|c|c|c|c|}
\hline Spectrum & $\mathrm{Al}$ & $\mathrm{Zr}$ & $\mathrm{Fe}$ & $\mathrm{Si}$ \\
\hline Spectrum 1 & 83.8 & - & 11.8 & 4.4 \\
\hline Spectrum 2 & 87.0 & - & 10.2 & 2.9 \\
\hline Spectrum 3 & 99.6 & 0.4 & - & - \\
\hline
\end{tabular}

Fig. 3 Microstructure of rods from alloy 1:

$a, b-\mathrm{SEM}$ of rods and grain structure after IRE; $c, d, e, f-$ annealing at $230,300,400,450{ }^{\circ} \mathrm{C}$

The microstructure of alloy 1 rods consists of an aluminum matrix and AlFeSi phases, zirconium is completely dissolved in the solid solution, no primary $\mathrm{Al} 3 \mathrm{Zr}$ crystals were found in the alloy structure (Fig. $3 a$ ).

The microstructure of alloys 2 and 3 consists of an $\alpha$-solid solution and eutectic phase inclusions, such as $\mathrm{Al}_{4}(\mathrm{Ce}, \mathrm{La})$ and $\mathrm{Al}-\mathrm{Fe}-\mathrm{Si}$, which is confirmed by the results of $\mathrm{X}$-ray microanalysis. In alloy 3, the volume fraction of eutectic phases is higher due to the higher concentration of alloying components (Fig. 5).

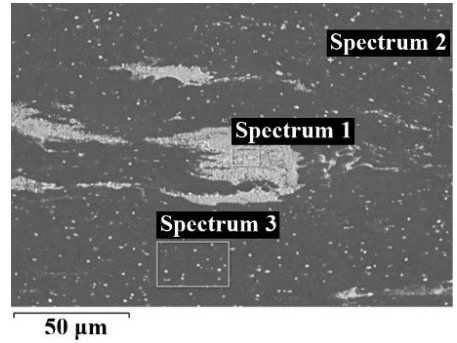

$a$

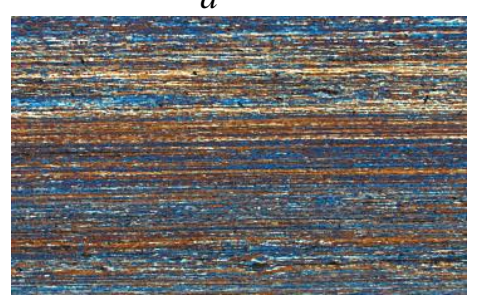

$\overline{500 \mu \mathrm{m}}$

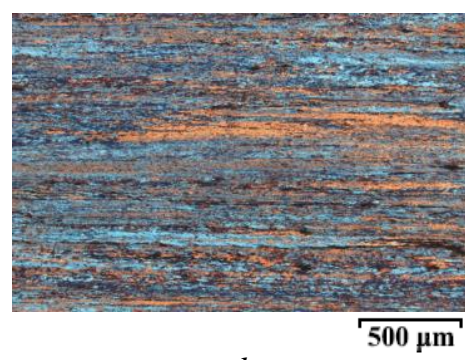

$b$

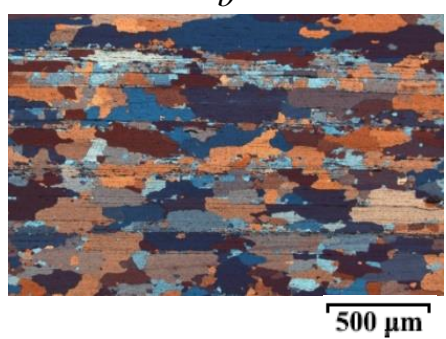

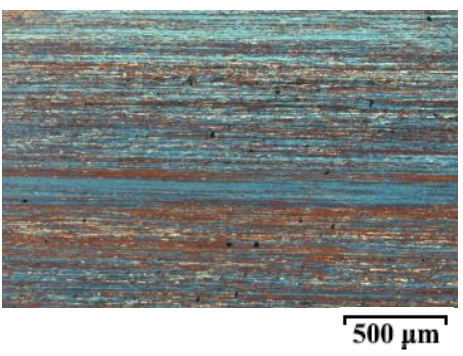

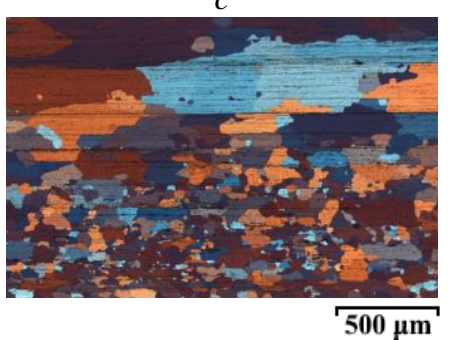

\begin{tabular}{|c|c|c|c|c|c|}
\multicolumn{2}{c}{$d$} & \multicolumn{2}{c|}{$f$} \\
\hline Spectrum & $\mathrm{Al}$ & $\mathrm{Ce}$ & $\mathrm{La}$ & $\mathrm{Fe}$ & $\mathrm{Si}$ \\
\hline Spectrum 1 & 79.1 & 12.2 & 7.3 & 1.0 & 0.5 \\
\hline Spectrum 2 & 84.1 & 8.9 & 5.4 & 1.0 & 0.6 \\
\hline Spectrum 3 & 99.0 & 0.5 & 0.4 & 0.1 & - \\
\hline
\end{tabular}

Fig. 4 Microstructure of rods from alloy 2:

$a, b-\mathrm{SEM}$ of rods and grain structure after IRE; $c, d, e, f-$ annealing at $230,300,400,450{ }^{\circ} \mathrm{C}$

In the rods of alloys 2 and 3 , there is an inhomogeneous distribution of phases over the cross section of the rod, namely, in the central zone of the rod, the eutectic phases are clustered in comparison with the peripheral zones in which they are fragmented and oriented in the direction of deformation. Annealing at $450{ }^{\circ} \mathrm{C}$ and holding for 10 hours leads to partial dissolution of accumulations of excess eutectic phases, after which the microstructure becomes more uniform. 


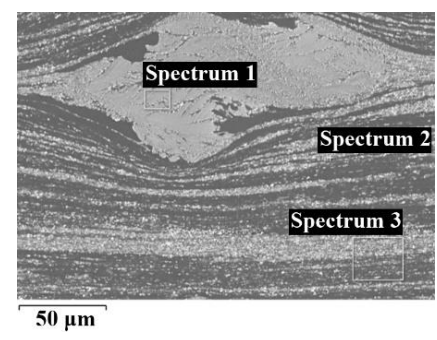

$a$

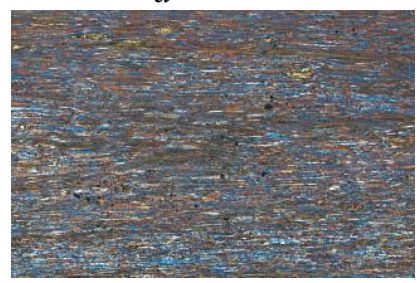

$\longdiv { 5 0 0 \mu \mathrm { m } }$

$d$

\begin{tabular}{|c|c|}
\hline Spectrum & \\
\hline Spectrum 1 & 8 \\
\hline Spectrum 2 & 65.5 \\
\hline Spectrum 3 & 90.5 \\
\hline
\end{tabular}

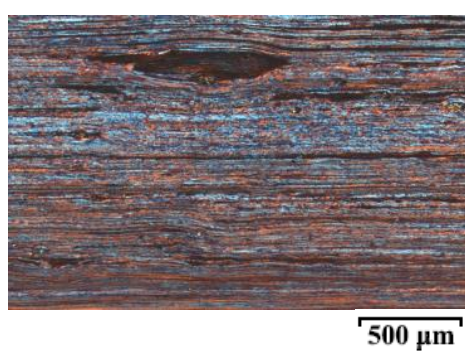

$b$

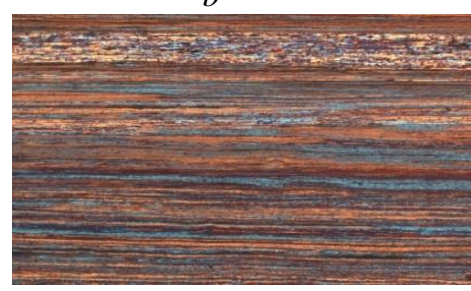

$500 \mu \mathrm{m}$

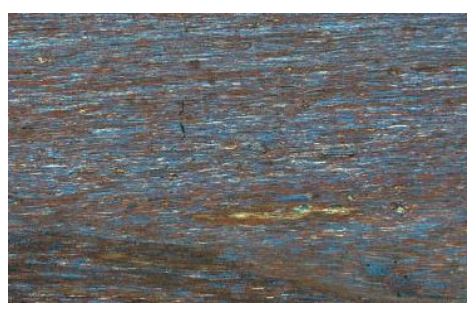

$\overline{500 \mu \mathrm{m}}$

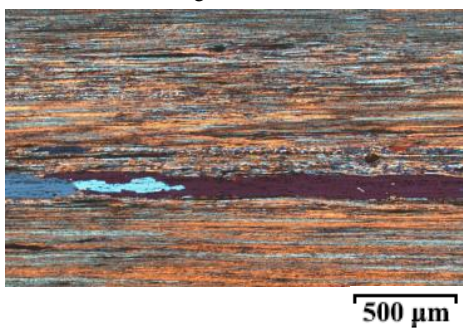

$f$

Fig. 5 Microstructure of rods from alloy 3:

$a, b-\mathrm{SEM}$ of rods and grain structure after IRE; $c, d, e, f-$ annealing at $230,300,400,450{ }^{\circ} \mathrm{C}$

An analysis of the grain distribution in the structure of the samples showed that, after annealing at 230-400 ${ }^{\circ} \mathrm{C}$ and holding for 1 hour, the rods of alloy 1 retain a fibrous deformed structure, after annealing at $450{ }^{\circ} \mathrm{C}$ and 10 hours the bar structure has a crystallized structure (Fig. $3 \mathrm{f}$ ), which indicates a loss of strength (table 2). The rods made from alloy 2 retain their structure to a temperature of $300{ }^{\circ} \mathrm{C}$ (Fig. 4 d), annealing at $400{ }^{\circ} \mathrm{C}$ and holding for 1 hour leads to recrystallization of the structure (Fig. $4 e$ ). Rods from alloy 3 retain the fibrous structure after annealing at $450{ }^{\circ} \mathrm{C}$ and holding for 10 hours, which indicates the high thermal stability of this alloy (Fig. $5 f$ ).

\section{Conclusion}

Performed studies allowed assessing the level of properties of rods from alloys with different chemical composition after processing by method of ingotless rolling-extruding and annealing:

- Ultimate tensile strength of rods made of an alloy with an addition of zirconium $0.3 \%$ is 140 $\mathrm{MPa}$, the introduction of $0.5 \%$ cerium with an alloy composition provides a strength level of 115 $\mathrm{MPa}$, and an increase in cerium concentration to $4.58 \%$ leads to a significant increase in this indicator to $190 \mathrm{MPa}$.

- The processing of experimental alloys by the IRE method provides good plastic properties of the rods, since the level of elongation to failure in the deformed state is $20-25 \%$.

- Electrical resistivity after the IRE is in the range $0.0310-0.0330 \mathrm{Ohm} \cdot \mathrm{mm}^{2} / \mathrm{m}$, subsequent annealing leads to a decrease in the value of this indicator to $0.0287-0.0319 \mathrm{Ohm} \cdot \mathrm{mm}^{2} / \mathrm{m}$.

- The alloy content of $0.3 \%$ zirconium ensures the preservation of the strength of the rods after annealing at $300{ }^{\circ} \mathrm{C}$ for one hour at a level of $120 \mathrm{MPa}$, and the addition of $0.5 \%$ cerium $110 \mathrm{MPa}$ after annealing $230^{\circ} \mathrm{C}$.

- The structure of rods from alloys containing cerium is characterized by the presence of clusters of eutectic phases located in the central part of the product, however, annealing at 450 ${ }^{\circ} \mathrm{C}$ for 10 hours leads to the dissolution of excess phases and the formation of a more uniform structure, while the ultimate tensile strength remains at $140 \mathrm{MPa}$, elongation to failure $40 \%$, electrical resistivity $0.0310 \mathrm{Ohm} \cdot \mathrm{mm}^{2} / \mathrm{m}$. 


\section{Acknowledgment}

The reported study was funded by Russian Foundation for Basic Research, Government of Krasnoyarsk Territory, Krasnoyarsk Regional Fund of Science to the research project: «Development resource-saving technology of combined casting, rolling and extruding of deformed semi-finished products from new aluminum alloys for the production of cable and wire products with high heat resistance», grant № 18-48-243006.

\section{References}

[1]S.B. Sidelnikikov, N.N. Dovzhenko, N.N. Zagirov. Combined and complex methods of machining non-ferrous metals and alloys, M.: MAKS PRESS, 2005.

[2]V. Bespalov, S. Sidelnikov, D. Voroshilov [and others]. Study of the Influence of Conditions of Combined Casting and Rolling-Extruding and Two-Stage Annealing on the Structure and Properties of Semi-Finished Electrical Products from an Al-Zr System Alloy. Key Engineering Materials. 805 19-24.

[3]S. Sidelnikov, R. Galiev, A. Bersenev, D. Voroshilov. Application and Research Twin Roll Casting-Extruding Process for Production Longish Deformed Semi-Finished Products from Aluminum Alloys. Materials Science Forum. 2018. Vol. 918. pp 13-20.

[4]S.B. Sidelnikov, N.N. Zagirov, E.S. Lopatina, R.I. Galiev, E.A. Rudnitskiy, D.S. Voroshilov, A.S. Sidelnikov. Prediction of metal properties during combined processing of Al - REM alloys based on a stage assessment of their mechanical characteristics. Izvestiya vysshikh uchebnykh zavedeniy. Tsvetnaya metallurgiya. 2015. № 4. pp 32-37.

[5]Anthony De Luca, David C. Dunand, David N. Seidman. Mechanical properties and optimization of the aging of a dilute $\mathrm{Al}-\mathrm{Sc}-\mathrm{Er}-\mathrm{Zr}-\mathrm{Si}$ alloy with a high $\mathrm{Zr} / \mathrm{Sc}$ ratio. Acta Materialia. 2016. Vol. 119, pp 35-42.

[6]N.A. Belov A.N. Alabin A.R. Teleuova. Comparative analysis of alloying additives as applied to the production of heat-resistant aluminum-base wires. Metal Science and Heat Treatment. 2012. Vol. 53, Issue 9-10, pp 455-459.

[7]E. Çadirli, H. Tecer, M. Şahin, E. Yilmaz, T. Kirindi, M. Gündüz. Effect of heat treatments on the microhardness and tensile strength of Al-0.25 wt.\% $\mathrm{Zr}$ alloy. Journal of Alloys and Compounds. 2015. Vol. 632, pp 229-237.

[8]A. Mogucheva, D. Zyabkin, R. Kaibyshev. Effect of the thermomechanical processing on microstructure and properties of an Al-Ce alloy. Materials Science Forum. 2012. Vol. 706-709, pp 361-366.

[9]H. Liao, Y. Wu, Y. Wang. Microstructure evolution of Al-0.35\%Si-0.2\%Mg-0.3\%Ce alloy during hot extrusion and its contributions to performances. Journal of Materials Engineering and Performance. 2015. Vol. 24, pp 2503-2510.

[10] N.A. Belov, N.O. Korotkova, A.N. Alban, S.S. Mishurov. Influence of a silicon additive on resistivity and hardness of the Al-1Fe-0.3Zr alloy. Russian J. Non-Ferrous Met. 59(3) 276283.

[11] Liao H., Liu Y., Lü C., Wang Q. Mechanisms for Ce-induced remarkable improvement of conductivity in Al alloys. Journal of Materials Research. 2017. Vol. 32, Issue 3, pp 566-574.

[12] Shi Z.M., Gao K., Shi Y.T., Wang Y. Microstructure and mechanical properties of rareearth-modified Al-1Fe binary alloys. Materials Science and Engineering: A. 2017. Vol. 632, pp 62-71.

[13] Zhang J., Wang H., Yi D., Wang B., Wang H. Comparative study of Sc and Er addition on microstructure, mechanical properties, and electrical conductivity of Al-0.2Zr-based alloy cables. Materials Characterization. 2018. Vol. 145, pp 126-134.

[14] Gao T., Ceguerra A., Breen A., Liu X., Wu Y., Ringer S. Precipitation behaviors of cubic and tetragonal Zr-rich phase in Al-(Si-)Zr alloys. Journal of Alloys and Compounds. 2016. Vol. 674, pp 125-130. 